\title{
A hipótese de Gaia a partir da individuação dos seres viventes de Gilbert Simondon
}

\author{
ÁDAMO BOUÇAS ESCOSSIA DA VEIGA *
}

\begin{abstract}
RESUMO O presente artigo pretende analisar a hipótese de Gaia de James Lovelock sob a ótica do problema da individuação em Gilbert Simondon. A hipótese de Gaia, que postula uma interação ativa entre todas as esferas do planeta e a vida, põe em cheque a perspectiva moderna sobre a natureza - que a coloca como passiva, inerte, mero palco para a conquista prometaica do gênero humano. A emergência de um novo regime climático é prova de que a Terra age sob a vida e vice-versa, não sendo mais mero palco, mas, igualmente, agente. $\mathrm{O}$ que pretenderemos será a partir de Lovelock e da análise de Latour sob Gaia, mostrar como o conceito de individuação em Simondon se adequa a hipótese de Lovelock de tal modo a mostrar como o seu conceito de indivíduo e vida nos permitem pensar Gaia como um indivíduo vivente.
\end{abstract}

PALAVRAS-ChAVE Simodon, Gaia, Lovelock, Latour.

\section{INTRODUÇÃO}

A hipótese de Gaia, proposta por James Lovelock, após uma longa e conturbada trajetória, obtém uma possível aceitação nos meios científicos e filosóficos. Com efeito, trata-se de uma descoberta - como coloca Latour (2015) - próxima a de Pasteur e Galileu; uma série de agentes, de efeitos, tornam-se reconhecíveis sobre um nome comum capaz de expressar a sua relação. Gaia é uma verdadeira inflexão no pensamento, na medida que nos permite pensar a relação entre diversos agentes em uma escala antes impensável. A hipótese de Gaia postula, a partir de observações e modelos científicos, a co-evolução entre vida e planeta, de tal modo que este em sua totalidade poderia ser

* Doutorando | Programa de Pós-Graduação em Filosofia | PUC-RIO Bolsista CAPES 
considerado um único indivíduo vivente - o atual equilíbrio climático, ao invés de depender exclusivamente de fatores de ordem geológica, se articula sobre a composição de fatores biológicos, geofísicos e atmosféricos. Gaia nos revela a especificidade do nosso planeta em relação aos demais, oferecendo, então, uma nova perspectiva eminentemente transdisciplinar cujo maior mérito é nos oferecer uma valiosa ferramenta para pensar e agir diante do advento de um Novo Regime Climático.

O presente trabalho procurará analisar a hipótese de Gaia sob o ponto de vista da análise da individuação em Gilbert Simondon. Para tal, nos valeremos não apenas das formulações de Lovelock, mas, igualmente, do desenvolvimento teórico que Bruno Latour dá a elas. A relevância de tal análise se situa na insuficiência de certo critério de individualidade - ao qual, após dois milênios de domínio teorético, se tornou o senso comum - de dar conta da possibilidade de todo sistema planetário ser um único indivíduo, Tal critério postula como fator determinante da individualidade uma substância, essência, forma ou matéria, dentre diversas outras formulações que têm em comum um princípio de individuação anterior ou posterior ao indivíduo; deste modo, este derivaria de processos exógenos, transcendentais em relação a ele. A partir desta abordagem, torna-se difícil conceber Gaia enquanto indivíduo, pois justamente, a sua individualidade se dá enquanto processo, agência, e não substância. Apenas certas interpretações, de todo modo estranhas à formulação científica de Lovelock, situam Gaia sob este aspecto, como se se tratasse de uma entidade sobrenatural, espírito da Terra, velha Mãe Natureza. Ora, a fim de evitar tais equívocos faz-se justificada uma interpretação de Gaia a partir de um critério de individuação outro, tal como o que propõe Gilbert Simondon. A compatibilidade entre o seu pensamento e a hipótese de Gaia será observada pelo ponto de contato mais evidente entre elas, a saber, a influência do pensamento cibernético em ambos autores. Utilizaremos o critério de individuação vivente de Simondon para pensar Gaia, tanto a de Lovelock quanto a da interpretação bastante rica de Bruno Latour.

Antes, no entanto, é necessário frisar que nem Lovelock, nem Latour afirmam diretamente que Gaia consiste em único indivíduo ou mesmo em um ser vivo; ela age como se fosse um, apenas. Veremos ao longo deste trabalho como a partir de um critério outro de individualidade, oferecido pela filosofia de Simondon, que o ser de algo- o ser não-vivente, o ser vivente - é o seu próprio como. Para Simondon, o indivíduo é processo em um regime determinado, não sendo nada além deste mesmo processo, de 
um como, que o institui em ato. Assim, dizer que Gaia age como um ser vivo e que Gaia é um ser vivo, dentro do escopo do pensamento de Simondon, é afirmar o mesmo.

\section{A HIPÓTESE DE GAIA: LOVELOCK E LATOUR}

A hipótese de Gaia tem sua origem nas pesquisas realizadas por James Lovelock na busca de um critério adequado para deduzir a presença ou ausência de vida em um planeta. Tal critério figuraria na presença, na atmosfera do planeta, de um desequilíbrio dinâmico provocado pela produção de gases pelos organismos vivos: "se o planeta não tivesse vida, então a atmosfera estaria próxima do equilíbrio.” ${ }^{1}$ Um planeta morto apresentaria um equilíbrio químico na composição da atmosfera, apresentando uma concentração de gases estável, dirigida pela lei do acréscimo de entropia. Importante evidência da hipótese de Gaia veio justamente da comprovação de que atmosfera de Marte é precisamente assim², ao passo que a nossa, pelo contrário, está em um desiquilíbrio dinâmico. A partir de tal observação, Lovelock conclui que não só a vida mantém os gases atmosféricos em desiquilíbrio, mas que tal desiquilíbrio retroage sobre a vida ao tornar as condições térmicas do planeta ideais à preservação da mesma. No caso do nosso planeta, o aquecimento esperado do Sol desde que a vida surgiu teria levado a um aumento térmico muito maior se não fosse a ação dos organismos. Então, inicialmente, o cientista postulou a utilização da atmosfera pela biosfera de modo a manter ótimas as condições para a sua sobrevivência; visão esta, que, no entanto, será complementada e expandida posteriormente. A regulação térmica não é operada apenas pela vida, "mas todo o sistema Terra que efetua a regulação.”3 Neste momento, a teoria de Gaia abandona a distinção entre vida e meio para nos mostrar como os dois obedecem a um regime de causalidade múltipla e horizontal; o sistema, Gaia mesma, é constituído pelo regime de ações tanto do organismo quanto do meio, sem que um lado possua um privilégio causal sobre o outro. A vida e a terra evoluíram juntos desde o seu surgimento, de tal modo que o planeta inteiro pode ser considerado como um sistema vivo.

\footnotetext{
1 Lovelock, 2010, p. 160

2 Idem

3 Ibidem, p. 160
} 
Lovelock nos coloca a seguinte definição: “nós definimos Gaia como uma entidade complexa envolvendo a biosfera, atmosfera, oceanos e solos da Terra; a totalidade constituindo um feedback ou sistema cibernético que procura o ambiente químico e físico ótimo para a manutenção da vida neste planeta." " Gaia é um regime de causalidade - feedback positivos e negativos - que, enquanto sistema autorregulado, permite a manutenção da vida. Por feedback positivo e negativo devemos entender certo desvio em um sistema, que no primeiro caso, se vê amplificado por si mesmo e, no segundo, diminuído. Lovelock nos oferece o exemplo de um termostato em um fogão comum; quando a temperatura alcança certo nível, o aquecimento é desligado, de tal modo que, após um breve aumento residual de temperatura, esta caia para o nível anteriormente definido; estando abaixo, ele é novamente ativado. Trata-se de um exemplo de feedback negativo ${ }^{5}$. Um exemplo de feedback positivo seria como uma bola de neve que desce da montanha; quando maior é a sua velocidade e espaço percorrido, maior o seu tamanho. Neste sentido, estamos, com efeito, em um feedback positivo em termos ecológicos, pois o aumento do calor produzido pela emissão de gases fósseis é exponencial; mais calor gerando mais calor, como coloca o próprio Lovelock:

O grande sistema da Terra, Gaia, quando em um período interglacial como agora, vê-se aprisionado em um ciclo vicioso de feedback positivo, e é isso que torna o aquecimento global tão grave e tão premente. Calor extra de qualquer fonte seja de gases do efeito estufa, do desaparecimento do gelo do Ártico e mudança de estruturas do oceano, ou da destruição de florestas tropicais - é aumentado, e os efeitos são mais do que cumulativos. ${ }^{6}$

A atividade industrial humana, com a emissão de gases fósseis, desmatamento e destruição da vida nos mares, leva a um feedback positivo no sentido de um aumento térmico. É um novo desequilibro que se encontra na eminência de comprometer o mecanismo de autoregulação em curso desde o surgimento da vida. Esta, com efeito, figura tal como o termostato descrito acima, o que Lovelock demonstra a partir da simulação do Mundo das Margaridas. ${ }^{7}$ Trata-se de uma modelização simples, na qual um planeta com exposição ao calor estelar, em aumento constante, é habitado por

\footnotetext{
4 Ibidem, p.10

5 Ibidem, p. 46

6 Lovelock, 2006, p. 20

7 Lovelock, 2010.
} 
dois tipos de margaridas: brancas e negras. As brancas refletem o sol, contribuindo para esfriar o planeta; as negras, ao contrário, absorvem a radiação estelar, aumentando a temperatura do planeta. No primeiro caso, as margaridas oferecem um feedback negativo na medida em que corrigem o aumento da temperatura por conta da sua capacidade de refletir a radiação solar; as segundas, um positivo, pois aumentam o calor vindo da estrela na medida em que o absorvem. Supondo um primeiro momento em que a temperatura planetária esteja abaixo do ótimo para ambas as flores, as de cor escura possuem uma vantagem competitiva, pois aumentam a temperatura de tal modo que, com o passar do tempo, tornam-se dominantes, cobrindo toda a superfície, até que por fim, isto gera tal aumento térmico que começa a favorecer as brancas - refletoras da radiação, e enquanto tal, capazes de produzir resfriamento - até que estas se tornam elas mesmas dominantes. O que a simulação demonstra é a interação entre feedback positivo e negativo - operado por seres vivos - sobre o clima em nível planetário: "O Mundo das Margaridas é o modelo de um sistema emergente no qual clima e organismos estão firmemente acoplados e evoluem juntos.” ${ }^{8}$

Deste modo, podemos ver, neste modelo, a correlação entre evolução biológica e temperatura planetária; no mundo real, para além destes fatores, muitos outros intervém. Cabe agora vermos como tais considerações levam à conclusão da Terra enquanto um ente que age como um sistema vivo. Como também já pudemos ver, é grande a influência da cibernética em toda hipótese de Gaia; no primeiro artigo relevante sobre o tema, Lovelock e Margulis(1974) já se referiam a esta área do conhecimento, e em Gaia: new look in life on Earth (2000), há um capítulo inteiramente dedicado a ela. Assim, a concepção de vida que permite tal conclusão será justamente aquela da cibernética, definida enquanto atividade neguentrópica, uma atividade capaz de reverter a entropia. Norbert Wiener (1990) já definia a atividade vital assim, e Lovelock e Margullis, no citado artigo, nos dizem que, por mais que fenômenos inorgânicos possam apresentar entropia decrescente, "a vida difere destes processos primitivos de steady state, pela singularidade, persistência e tamanho da redução de entropia que ela sustenta." 9

8 Ibidem, p. 169

9 Lovelock, Margullis, 1974, p.2 
Mais adiante, os autores completam dizendo que a "recognição de uma entidade viva pode ser baseada na extensão do seu desiquilíbrio físico e químico.” ${ }^{10}$ Assim, a vida se caracterizaria pela manutenção de um desiquilíbrio neguentrópico, cuja expressão mais direta é a homeostase - a regulação térmica ativa do organismo contra a tendência ao equilíbrio. Tal ponto é bastante relevante para o nosso propósito aqui, pois tal formulação acerca do vivente é em tudo similar à de Gilbert Simondon.

Uma das mais notáveis consequências de tal visão é que ela põe em cheque a divisão tipicamente moderna entre vida e meio, e mais contundente ainda, entre natureza e humano. Como coloca o próprio Lovelock sobre a hipótese de Gaia: “ela é uma alternativa à visão pessimista que vê a natureza enquanto uma força primitiva a ser subjugada e conquistada." 11 A natureza reage sobre a vida e sobre a atividade humana, reação esta que a mudança do regime climático a partir dos resíduos da produção industrial vem sobremaneira demonstrar. A natureza não é mais passiva, nem antitética ao homem; não é mais a alteridade inanimada ou o palco para a conquista prometeica da espécie humana. Ela é, com efeito, um ser que age como ${ }^{12}$ um indivíduo vivente e enquanto tal, um agente tal como nós somos e no qual nós nos vemos inseridos.

É este ponto que será priorizado por Latour, sobretudo em seu livro Face à Gaia (2015). O que Latour pretende demonstrar é como a imagem do Globo - de um todo unificado, maior que as partes - é inadequada para se pensar Gaia e a emergência de um novo regime climático. O programa teórico de Latour, a sua teoria do ator-rede, como exposto sobremaneira em Reassembling the Social (2005) é destituir a proeminência do todo sobre as partes e ao mesmo tempo que refutar uma substancialização do social. Para o autor, tudo que é, é aquilo que age, fórmula essa tirada de Gabriel Tarde, pensador cujo Latour se refere como seu "avô teórico."13 Gaia, então, longe de ser um Todo, é uma composição de potência de agir, cujo efeito autoregulador não deriva da totalidade, mas, contrariamente, permite a sua emergência. É possível, a partir

10 Idem

11 Lovelock, 2000, p.11

12 Vale, novamente, ressaltar que Gaia, para Lovelock, não é um organismo vivente, mas um ser que age como ele. É justamente esse “como”, a homologia funcional, quer permite-nos afirmar,a partir de Simondon, que ela pode ser pensada como um ser vivente dado que este nada mais é, como veremos, do um processo análogo ao de Gaia enquanto agência neguentrópica.

13 Latour, 2016. 
de certas passagens de Lovelock, como o próprio Latour demonstra, interpretar Gaia como um superorganismo e como uma teleologia dos processos físicos, químicos e vitais da terra; superorganismo, pois seria uma vida composta de toda vida orgânica do planeta, todos os seus organismos; teleologia, pois ela possuiria e imporia o objetivo da regulação térmica sobre todo o planeta. Se Lovelock dá margem a esta interpretação, o faz apenas por um certo uso estilístico, percalço necessário para expressar a sua ideia e para divulgá-la para além dos meios rigorosamente especializados. Latour, fundamentando-se em diversas outras passagens de Lovelock, demonstra como tal interpretação é inadequada. Nas suas palavras:

O problema de Lovelock é novo: como falar da Terra sem tomá-la como um todo já composto, sem lhe imprimir uma coerência que ela não tem, e, portanto sem a desanimar fazendo dos organismos que a mantém viva a fina película de zonas críticas, simples passageiros inertes e passivos em um sistema físico-químico? Seu problema é sobretudo de compreender em que a Terra é ativa, mas sem lhe acrescentar uma alma. ${ }^{14}$

A Gaia de Latour é uma entidade emergente, uma totalidade performativa que apenas se diz das suas partes e nada mais. Há um regime complexo de interações entre diferentes potências de agir, cujo resultado - e não a causa - é Gaia:

Cada potência de agir modifica suas vizinhas, nem que muito pouco, para tornar a sua própria sobrevivência ligeiramente menos improvável. É aqui que se encontra a diferença entre geoquímica e geofisiologia. Isto não quer dizer que Gaia possui uma espécie de grande alma sensível, mas que o conceito de Gaia captura a intencionalidade distribuída de todos os agentes onde cada um modifica seu entorno segundo a sua conveniência. ${ }^{15}$

Gaia torna-se profana na medida em que, simultaneamente, rechaça uma "superanimação da natureza” - ao modo de uma interpretação religiosa, mística - e, ao mesmo tempo, uma “desanimação” ao modo da ciência moderna, segundo a qual a parte não animado do universo é amputada de toda agência e reação. Profana, pois ambos os casos não são nada senão religiosos; emergem da concepção teológica cristã, que postula um deus único exterior ao mundo - mundo que devém, assim, inanimado, passivo, determinado de forma exógena. Na verdade, o termo religião, como o autor demons-

\footnotetext{
14 Ibidem, p. 69-70

15 Ibidem., p.77
} 
tra, é inadequado para se referir a tal concepção; a partir do que Michel Serres analisa do tema, religião significa inicialmente reunir(assembler) ou "designar aquilo que alguém tem, que protege com cuidado, que se evita negligenciar.”16 A relação entre religião e verdade, nesta concepção, é outra, no sentido de que a religião não é a detentora da verdade última, ao modo de uma revelação dada a um coletivo específico. $\mathrm{Na}$ antiguidade romana, havia tábuas de tradução nas quais diferentes deuses, com base nos seus atributos, eram identificados permitindo o seu culto em diferentes templos: o deus grego Zeus era Júpiter para os romanos, por exemplo. O que sinaliza Latour - e aqui está a relevância desta consideração - é que o que importava é que a divindade era reconhecida não por uma identidade essencial e inalienável, mas por suas imputadas ações - controle dos oceanos, da fertilidade, etc; não havia algo como uma substância, mas tão apenas os seus atributos. A substancialização, a preeminência do Todo como determinante em relação às partes, seria uma contra-religião, pois impediria a tradução com base nos atributos em prol de uma identidade totalizante intraduzível. Ao invés do ponto de vista parcial de diversos povos sobre as entidades divinas - ponto de vista de cada povo, cada coletivo - teríamos, então, nesta contra-religião, uma visão global, ponto de vista de deus, que tornaria todos os outros como falsos.

Tal movimento é o que Latour, demonstrando como ele se mantém sobre diferentes roupagens no Ocidente, mesmo na ciência, pretende romper quando nos fala de Gaia. Assim, em uma inflexão com a visão contra-religiosa descrita acima, "as divindades, como os conceitos, como os heróis da história, como os objetos do 'mundo natural' - inundações, rochas, rios, hormônios, levuras - não possuem competência - e, assim, substância - senão pelas performances - pelos atributos - que lhes dão forma in fine." ${ }^{17}$ A imagem da natureza ou da cultura enquanto árbitro de qualquer disputa, como ponto de vista global, se associa à ideia de um deus único. Gaia, feita profana, vem justamente destituir este ponto de vista global e externo, demonstrando como tudo que emerge, emerge da agência local de potências de agir. Gaia torna-se, como uma antiga divindade, a soma dos seus atributos.

A partir destas considerações Latour rejeitará a herança cibernética de Lovelock. A cibernética, de fato, tem sua origem sobre um horizonte técnico voltado ao con-

16 Ibidem p. 117

17 Idem 
trole, a criação de máquinas mais eficientes e de ação mais precisa. Tal concepção seria alheia a Gaia, pois esta não foi feita por ninguém, não é obra de um engenheiro divino ou secular - seja deus, a seleção natural ou o que quer seja. Sua contingência, assim como a sua pluralidade de agentes, interditariam uma concepção cibernética na medida mesma em que interditam a pretensão de um controle. Diferentemente de Lovelock, Latour rejeita a possibilidade de uma geoengenharia - o controle das condições climáticas através de uma intervenção técnica, como a emissão de gases outros para combater o efeito estufa. ${ }^{18}$

A grande diferença entre as duas leituras, a de Lovelock e a de Latour, nos parece ser que a primeira parte de um ponto de vista um tanto exterior (transcendente), enquanto discurso científico que se mantém até certo ponto separado daquilo que estudo ao passo que o segundo parece negar esta exterioridade propondo um ponto de vista interior (imanente) - parcial, contingente, emergente. Não há qualquer oposição aqui, mas antes Latour parece estar trabalhando a hipótese científica de Gaia sob um ponto de vista filosófico e não apenas científico. Nesta mesma chave, a totalidade da visão científica - o ponto de vista de deus - é substituída pelo ponto de vista local e relativo - a multiplicidade no lugar da unidade. No entanto, tal aspecto não nos parece incompatível com a cibernética, nem mesmo com a ciência; antes, nos parece uma inflexão interna à mesma, como veremos.

Sob este aspecto, nos parece muito interessante a reflexão da Niklas Schrape (2014) sobre a diferença entre a Gaia de Lovelock e a de Latour. Ele nos mostra como, de fato, a cibernética em voga na época de Lovelock - dita de “primeira ordem” - se preocupa, sobretudo, com a questão do controle. O próprio Mundo das Margaridas, com "seus loops de feedback, é produto de um engenheiro, eles exemplificam um mecanismo, eles não emergem de condições contingentes e mutantes." ${ }^{19}$ No entanto, a cibernética mesma começa a se afastar de tais questões, se focando em problemas de auto-organização e de emergência a partir de situações de alta complexidade. Se a Gaia de Lovelock permite uma engenharia "podendo ser descrita, analisada, e talvez mesmo

18 Ibidem, p. 203

19 Scrhape, 2014, p. 93 
construída”, a Gaia de Latour “é uma entidade sempre evoluindo e devindo, que emerge da interação co-evolucionária entre matéria viva e não viva.” ${ }^{20}$ Deste modo, Gaia não seria dada, não teria um fim, mas seria a emergência contingente e autopoiética, imanente, a partir de um jogo casual entre potências de agir distintas. Esta inflexão para a imanência e autopoiese, bastante marcada na interpretação latouriana, é bem relevante para o nosso propósito aqui, como veremos agora com Simondon.

\section{O PROBLEMA DA INDIVIDUAÇÃO EM SIMONDON.}

A filosofia de Simondon se pretende, em primeiro lugar, um pensamento da individuação,que, como vimos, nos oferece um critério outro do que é o indivíduo. Esta inflexão na metafísica tradicional nos parece adequada para pensar Gaia, pois em muito se aproxima da contribuição teórica de Latour, em seu movimento de suprimir a substância em prol da agência. Para Simondon, a filosofia sempre tentou explicar a individuação a partir dos seres já individuados, procurando neles um princípio anterior e determinante capaz de explicar o mecanismo da individuação antes da individuação propriamente dita. Através do recurso a um princípio primeiro - seja pelo átomo no caso do substancialismo atomista, ou pela dualidade forma-matéria no hilemorfismo - se toma a individuação como aquilo que deve ser explicado no indivíduo e não aquilo de onde provém a explicação para ele. Em ambos os casos, trabalhou-se sempre dentro de um “privilégio ontológico do indivíduo constituído” ${ }^{21}$ em detrimento da sua constituição.

O que Simondon pretende é inverter este privilégio. Trata-se de “conhecer o indivíduo através da individuação antes de a individuação através do indivíduo.”22 Simondon procura entender a individuação como um processo dinâmico, em ato, em vez de procurá-la em algum princípio explicativo anterior ou superior à própria individuação. Não se trata de abstrair do indivíduo sua forma e sua matéria, por exemplo, e supor sua individuação a partir da combinação das duas. Trata-se, antes, de pensar o movimento no qual ele adquire tanto sua forma como sua matéria, sendo que ele não pré-existe a este movimento. A individualidade de um ser ou outro em particular não

\footnotetext{
20 Idem.

21 Simondon, 2008, p.24

22 Ibidem, p. 26
} 
deriva de sua essência transcendente ou do encontro entre uma forma pura e uma matéria inerte, mas sim do processo relacional e dinâmico que o constitui ao mesmo tempo que constitui aquilo que lhe é exterior. A individualidade, deste modo, não vem de um "quê" enquanto essência ou propriedade, mas sim de um como. O individuo torna-se processo, processo de individuação. Assim, aquilo que Simondon pretende em sua obra, em primeiro lugar, é dar a individuação à ela mesma. Nas suas palavras:

A diferença entre o estudo clássico da individuação e o que nós apresentamos é essa: a individuação não será considerada unicamente sob a perspectiva do indivíduo individuado; será captada, ou pelo menos deverá ser captada, antes e durante a gênese do indivíduo separado; a individuação é um acontecimento e uma operação no centro de uma realidade mais rica que o indivíduo que resulta dela. $^{23}$

Deste modo, podemos ver aqui um ponto de convergência com Latour: a individualidade não decorre de nada para além de um processo atual de constituição; tal processo é uma agência, uma composição de ações e não supra-existe ou pré-existe a elas. Como coloca Simondon "o nosso trabalho deve realizar uma crítica dos universais, e particularmente colocar em questão o pensamento que supõe a classificação por gêneros comuns e diferenças específicas." ${ }^{24}$ A ontologia de Simondon é sobretudo uma ontologia da relação: “a relação tem estatuto de ser”. Tudo que é, não é em si, mas em outro, em uma cadeia relacional múltipla e complexa, semelhante, com efeito, às postulações de base da teoria do ator rede de Latour. Podemos já ver aqui, como mesmo que Latour e Lovelock nos digam que Gaia não é um ser vivo ou indivíduo, mas age como um, a concepção de indivíduo em Simondon é precisamente a de um como, uma ação e processo, de tal modo a ser possível, então, enxergar em Gaia um indivíduo.

Para Simondon, tal reversão do conceito de indivíduo, de uma abordagem essencial e substancialista para uma dinâmica e processual, se torna possível a partir da invenção de um conceito científico: a metaestabilidade. Criado pela termodinâmica, ele exprime um sistema passível de mudança através da solução de uma disparidade energética, uma disparidade entre duas ordens de grandeza. Um sistema metaestável é aquele que ainda não alcançou seu grau máximo de estabilidade, e assim, mediante

23 Ibidem, p.83

24 Ibidem, p.523 
um aporte de energia externo ou algum evento interno, muda de fase, se transforma, passando para um estado mais estável, instável ou mesmo, igualmente, metaestável. Em última instância, o estado mais estável corresponde a um índice máximo de entropia, uma indisponibilidade de conversão de energia em trabalho, incapacidade de sofrer qualquer transformação. É o “equilíbrio que se alcança quando todas as transformações possíveis foram realizadas e já não existe nenhuma força.”25

O estado metaestável corresponde ao que ele chama de pré-individual, estado contemporâneo a qualquer individualidade/individuação de onde esta retira a sua diferença constituinte. Do pré-individual - a que ele se refere como sendo o próprio ser em alguns momentos - temos, a partir da solução da sua disparação e diferença, um caso mais estável enquanto solução que corresponde a tal indivíduo. A contemporaneidade do pré-individual ao ente individuado está em seu potencial de transformação e mudança de fase. A solução da diferença em um caso de identidade nunca o esgota - ao menos enquanto não chegarmos a um máximo de entropia em escala cosmológica - de tal modo que é sempre possível uma nova individuação a partir da atualização destes outros potenciais ainda disponíveis. Neste ponto, há uma diferença crucial e sobremaneira importante para nossos propósitos aqui entre a individuação do ente físico e do vivente. Este último mantém uma rigorosa atualidade, não se diz para além do seu processo ativo de autopoiesis, ao passo que o primeiro se constitui em um único lance. Veremos, agora, como esta diferença se dá em mais detalhe.

A individuação em Simondon é pensada, primeiramente, a partir da física. Dela, ele extrairá o modelo posteriormente aplicado aos seres viventes e, dentre estes, os humanos. Em ambos os casos, no entanto, ela obedece ao regime de três caracteres coextensivos a toda individuação: uma energética, uma estrutura e um regime acontecimental.

O regime energético corresponde à disparidade constituinte do pré-individual, à presença de potenciais ainda não efetuados. A estrutura corresponde à solução deste potencial, sem que, no entanto, ele se esgote; ele se mantém paralelamente, é condição virtual da estrutura. A individuação enquanto ato relacional é sobretudo relação de uma materialidade com uma energética. A estabilidade relativa de qualquer estrutura

25 Ibidem.,p. 28 
é referida a uma condição dinâmica e, por outro lado, modificações desta estrutura são indissociáveis de uma variação intensiva. Trata-se de uma dualidade de circunstâncias presentes em cada indivíduo. Escreve Simondon:

Os limites do domínio de estabilidade de um tipo de estrutura são determinados por condições energéticas [...]; a toda estrutura está ligado um caráter energético, e, inversamente, a toda modificação das condições energéticas de um sistema físico pode corresponder uma mudança do carácter estrutural deste sistema. ${ }^{26}$

A presença de potenciais, enquanto possibilidade de mudança de sistema, só se expressa nesta própria mudança; mas, de forma latente, se mantém na estrutura enquanto limite do domínio de estabilidade. Simondon nos oferece um exemplo privilegiado: o da formação cristalina. A cristalização nada mais é do que a organização de moléculas desorganizadas em uma estrutura geométrica precisa e é exemplo notável de uma ontogênese estrutural no domínio físico.

A cristalização começa com a sobressaturação de uma substância química por conta da temperatura ou da pressão. É um estado instável, no qual as suas moléculas constituintes se chocam, transferindo calor umas às outras. Esta instabilidade corresponde ao lado propriamente energético e, como vimos, terá uma estrutura correlata - no caso, a organização não-cristalina, amorfa, da substância sobressaturada. Esta agitação, no entanto, não é suficiente para que haja a cristalização. Para que da disparidade energética e do suporte material surja o cristal enquanto indivíduo é necessária a intervenção de um fator acontecimental. Para que a disparidade energética entre estruturas ou no interior de uma própria estrutura tenha valor constitutivo é fundamental que a "energia possa ser atualizada pela estrutura, em função das condições materiais locais.” ${ }^{27}$ Estas condições materiais locais correspondem, no exemplo, à presença de gérmens cristalinos, singularidades que aportarão na direção da individuação do sistema. Nesta situação específica, são moléculas já organizadas segundo a forma cristalina.

26 Ibidem.,p. 105

27 Ibidem, p.122 
Os primeiros cristais estruturados são um gérmen estrutural a partir do qual toda a substância se estrutura; eles in-formam ${ }^{28}$ a matéria através da sua amplificação estruturante. O gérmen estrutural conjuga a energética com a materialidade, permitindo a atualização da última na primeira. Ele aponta na direção da atualização dos potenciais latentes em estrutura, “definindo a interioridade mútua de uma estrutura e de uma energia potencial no interior de uma singularidade." ${ }^{29}$ Não é matéria nem forma, mas informação, modulação. Esta operação é transdutiva; relação constituinte de termos e não relação entre termos. Só há termos a partir da ressonância interna do gérmen; neste sentido, ele opera a polarização de uma matéria amorfa.

Não se trata da quantidade de energia escalar da energia potencial, nem das puras propriedades materiais, nem das puras propriedades vetoriais, da estrutura portada pelo gérmen, mas sim de uma relação de terceiro tipo, que pode se chamar analógica, entre as estruturas latentes da substância ainda amorfa e a estrutura atual do gérmen. Esta condição é necessária para que possa haver ali uma verdadeira relação amplificante entre esta estrutura do gérmen e esta energia potencial carregada por uma substância amorfa. ${ }^{30}$

A expansão do gérmen não tem limite interno. É suscetível de expansão indefinida, só sendo interrompida pela oposição exterior ou pelo esgotamento do material ou da energia disponíveis no meio amorfo. Esta ausência está assimilada à capacidade, nos sistemas físicos, de receberem apenas uma única informação. A individuação se dá em único lance, propagando-se o gérmen até onde ele pode. Os limites são dados por fora; qualquer ser, na realidade, existe sob o seu limite que é onde se dá a sua polarização em relação ao meio. No entanto, a constituição de uma verdadeira individualidade é comprometida pela ausência de integração informacional do conjunto; na estabilidade, não temos mais informação, ela já foi consumida. Cada parte do cristal é interior e exterior às outras sem que isto institua um limite comum em relação ao cristal e ao meio; seu crescimento indefinido não permite a constituição de uma interioridade a partir de uma autolimitação. Por isto, ele não obedece a critério individual interno, sendo indissociável do meio. Isto será, com veremos, uma propriedade dos indivíduos vivos.

28 In-formar remete ao processo de tomada de forma, de gênese de forma.

29 Idem

30 Idem. 
Vimos que, no indivíduo físico inanimado, a informação se atualiza em uma forma única; os potenciais se resolvem uma única vez. O indivíduo físico não apresenta coincidência entre topologia e cronologia; esta é sua maior distinção em relação ao vivente. O passado de um cristal, a sua formação cristalina, estando esgotada no estado estável, não está verdadeiramente presente nele: “tem apenas um papel bruto de sustentação.” ${ }^{11}$ O tempo passado não é “condensado” em um cristal, pois, para Simondon o presente enquanto presentificação, individuação, é indissociável de um devir associado a um estado metaestável. A estabilidade, se a associarmos novamente à entropia, é indissociável de uma direção temporal definível; a questão da "flecha do tempo" ${ }^{32}$ se relaciona a uma estabilidade última como fim cosmológico inevitável. O passado se torna a reação irreversível, já dada, já acabada - e, neste sentido, é identificado a um ganho de estabilidade inversamente proporcional à disponibilidade de energia potencial para transformação. No caso do cristal, em escala menor, o ganho de estabilidade a partir da solução imediata da metaestabilidade, que não deixa mais potencial disponível, é o que lhe concede um passado verdadeiramente passado, que não atua mais no seu presente e não se prolonga no seu porvir.

Por outro lado, podemos afirmar que ele não possui uma verdadeira interioridade após o momento de transdução germinal-estruturante. Cada molécula cristalizada é exterior às demais, e o arranjo estrutural do cristal macroscópico é a mera sobreposição destas. Não há troca informacional entre elas, não há ressonância interna, mas apenas adição. O seu limite exterior não provém de uma operação interiorizante continuada; ele é dado unicamente no momento da individuação que se consuma de uma única vez.

A diferença entre um vivente e um cristal inerte consiste no fato de que o espaço interior do cristal inerte não serve para sustentar o prolongamento da individuação que se efetua nos limites do cristal em crescimento; a interioridade e a exterioridade só existem de capa molecular a capa molecular, de capa molecular já depositada a capa molecular depositando-se; [...]; o interior não é homeostático em seu conjunto em relação ao exterior. ${ }^{33}$

31 Ibidem, p.523

32 Ou seja, a entropia no final triunfa indicando uma direção irreversível do tempo correlata à irreversibilidade das transformações químicas, a indisponibilidade de energia para a mudança.

33 Ibidem, p. 239 
Diferentemente, o vivente é aquele que constitui uma verdadeira interioridade enquanto conserva em si a metaestabilidade. Há, de fato, uma continuidade entre o físico inorgânico e o vivente, mas há, igualmente, uma grande diferença de regime. Escreve Simondon:

A individuação vital não vem depois da individuação físico-química, mas durante esta individuação, antes de seu acabamento, suspendendo-a no instante em que ainda não alcançou seu equilíbrio estável, e fazendo-a se estender e se propagar antes da iteração da estrutura perfeita que pode apenas ser repetida ${ }^{34}$.

O vivente é um teatro de individuações contínuas que interrompem a degradação em direção à estabilidade. Assim, o “equilíbrio do vivente é um equilíbrio metaestável.”35 Há uma maior permanência do pré-individual, enquanto potencial disponível de transformação, o que permite que ele receba informação mais de uma vez, que sua ressonância interna se estenda para além de um momento estruturante inicial. Diferentemente do cristal, a estrutura do vivente é dada continuamente, constantemente. A função anabólica, a síntese proteica, a respiração celular, a integração nervosa, são processos de estruturação permanentes no seio do vivente. Isto supõe uma in-formação contínua. Ele é um conjunto de ações antes de ser uma substância. Neste sentido, ele possui uma verdadeira interioridade caracterizada "como unidade de um sistema de informação.” ${ }^{36}$ Ele a possui de fato, pois não é apenas composto pela sobreposição de partes, mas pela sua integração e diferenciação permanente. Integração aqui é entendida como armazenamento de potenciais e a diferenciação como a estruturação a partir destes potenciais; as duas estabelecem uma relação transdutiva. No caso meramente físico, “esta transdução é direta e em um único nível, enquanto no ser vivente ela é indireta e hierarquizada." 37 Ele comporta vários níveis, várias operações transdutivas simultâneas. Escreve Simondon:

A estrutura de um organismo completo não é somente a integração e a diferenciação; é também esta instauração de uma mediação transdutiva de interioridades e exterioridades que vão desde uma interioridade absoluta a uma

34 Ibidem, p.339

35 Idem

36 Ibidem, p, 430

37 Ibidem, p.239 
exterioridade absoluta, através de diferentes níveis mediadores de interioridade e exterioridade; poder-se-ia classificar os organismos segundo o número de mediações de interioridade e exterioridade que põem em marcha para o cumprimento das suas funções. ${ }^{38}$

Um organismo como o nosso é composto de infinitas mediações entre interioridade e exterioridade; um regime de informação, de determinação recíproca, organiza as células em um órgão, por exemplo, cuja unidade funcional lhe garante certa unidade relativa. Ele é exterior ao corpo, em certo sentido, sendo pertencente a ele em outro; a mediação transdutiva, dada por um regime informacional, é o que permite a integração dele em uma individuação mais ampla, a do próprio organismo. Como já vimos, é este regime que permite a coexistência de conjunto e subconjuntos. O aparelho nervoso central é o grande integrador da troca informacional nos seres viventes. Pode-se dizer que ele opera a ressonância interna, ou melhor, é a operação da ressonância interna. Diferentemente de um cristal, cujas partes interiores não são afetadas se batermos com uma picareta no seu limite exterior, um ser vivente será inteiramente afetado através da ressonância nervosa caso o atinjamos com a mesma picareta. No vivente, um acontecimento na parte é transmitido, integrado, no todo.

Simondon, a partir desta análise, afirma que a homeostase não é suficiente para definir o ser vivo. Esta, enquanto auto-regulação térmica, possui a sua importância, mas uma perspectiva que lhe dê o lugar determinante acaba por restringir a autopoiesis do vivente ao seu caráter individual; o ser vivente não pode ser pensando, segundo Simondon, sem que venha acompanhado do meio que lhe é associado. A individuação vivente é a individuação do organismo e do meio que lhe é associado; este não está em uma relação de absoluta exterioridade, ao qual caberia o primeiro se adaptar (Simondon, dedica um capítulo inteiro a problematizar a ideia de adaptação ao meio), mas, ao contrário, se define como uma mediação ativa entre a constituição recíproca de uma exterioridade - pela integração, e interioridade - pela diferenciação. Isto mostra como a noção de homeostase é insuficiente, pois a atividade autopoiética do vivente vai além da mera regulação térmica individual.

Como coloca Andrea Bardin sobre Simondon:

38 Idem. 
O ponto é: a complexidade do ser vivente não pode ser reduzida à homeostase do 'meio interno' porque esta depende da mudança de fase estrutural do sistema composto pelo indivíduo e o seu meio associado, o que só pode ser estabelecido a partir de uma série de subsequentes associações de estruturas e funções. Então, é finalmente possível entender por que na perspectiva de Simondon não podemos falar propriamente de uma homeostase do ser vivo. É evidente que múltiplos processos homoestáticos fazem-se coerentes em um sistema no qual o ser vivo é a (sempre parcial) metaesbilização através de um processo transdutivo de invenção. Esta repetição seria a de uma sempre singular invenção de novas compatibilidades entre organismo e meio, e não apenas o organismo, que é chamado de vida. ${ }^{39}$

Será este último ponto, principalmente, que nos permitirá fazer a aproximação entre o conceito de individuação vivente e a hipótese de Gaia.

\section{CONCLUSÃO.}

Após o exposto, deveremos agora analisar a relação entre a teoria da individuação de Simondon e hipótese de Gaia. Como vimos, o conceito de vida em Simondon se associa a uma atividade de integração e diferenciação que retarda a individuação mantendo um estado de metaestabilidade. Tal conceito, retirado da cibernética - a neguentropia como característica do vivente já em Norbert Wiener - tem o mesmo fundo teórico que a hipótese de Gaia de Lovelock que, como vimos, se baseia na mesma definição de vida. Gaia, enquanto organismo vivente, opera uma integração e diferenciação que prolonga a metaestabilidade; a biosfera recebe o calor do Sol, a energia é integrada, deixando potenciais disponíveis a serem diferenciados nas formas múltiplas dos seres orgânicos no planeta. E estes, por sua vez, agem de forma a manter um equilíbrio metaestável, como nos mostra Lovelock quando analisa o desiquilíbrio químico na atmosfera terrestre - justamente, a maior evidência da existência de Gaia. Ora, se o critério da individuação vivente é precisamente a permanência do desequilíbrio, o nosso planeta pode ser dito vivente na medida em que a aliança entre viventes e não-viventes tem por consequência a manutenção de um estado metaestável em nível planetário, o qual é condição para a própria manutenção da vida. Se Lovelock, nem Latour, afirmam diretamente que Gaia é um indivíduo vivente, mas algo que

39 Bardin, 2015, p. 78 
age como um, podemos ver que dentro da conceptualização particular de indivíduo vivente oferecida por Simondon, Gaia pode ser encarada deste modo.

Por outro lado, temos o critério da ressonância interna de informação, que diferencia uma individuação vivente de um meramente físico. Por mais que, no físico, tal ressonância manifeste-se em determinado momento - como na emergência do cristal do meio amorfo - ela se esgota de tal modo que não há verdadeira individualidade no domínio físico - nenhuma pedra de uma montanha dela se distingue senão a nossos olhos - ao passo que um vivente tem uma verdadeira individualidade assegurada pela ressonância interna de informação - a coordenação das agências na produção de um todo coerente. Aqui, a inflexão de Latour em relação a Lovelock nos é útil. Gaia, enquanto distribuição de agências, consiste em um regime de ressonância interna de informação, e não em um direcionamento superior como se o todo exercesse, transcendentalmente, uma coerção sobre a agência das partes. A emergência de Gaia sobre a terra se deu de forma imanente, e é apenas a partir das relações entre as suas partes - seus potenciais - que ela existe e se mantém em seu equilíbrio metaestável. O grau desta ressonância revela-se facilmente na medida em que vemos, com trágica clareza, como as ações locais dos humanos levam a consequências globais: o plástico jogado no mar da China assassina peixes e cetáceos na América Latina. O impacto da sociedade industrial sobre o clima planetário só é possível por esta grande ressonância interna de informação, o que justifica, sem dúvida, os receios de Latour quanto à geoengenharia: difícil, quase impossível, prever o que uma tal manipulação poderia produzir, do mesmo modo que no caso bem limitado de organismo vivo, é sempre difícil e arriscado prever o que advém de um transplante de órgãos.

O fato de a individuação dos viventes ser uma operação constitutiva de indivíduo e meio aproxima bastante o pensamento de Simondon à teoria de Gaia, pois esta, justamente, se baseia na co-evolução entre vida e meio. A distinção entre os dois, o recorte entre vida e ambiente, se dilui na medida em que os dois se integram em um sistema mais amplo. Gaia, pelo que expomos acima, é um indivíduo vivente em nível planetário. É o regime de ressonância interna entre os organismos orgânicos em geral, a biosfera, e os indivíduos físicos, a geosfera, a atmosfera. Vimos como o indivíduo vivente é uma mediação ativa e constitutiva de uma interioridade e exterioridade, e, como tal, não estando à parte do seu meio, está a ele ligado na relação duplamente 
constitutiva do mesmo modo que, em Lovelock, o meio não-vivente e o vivente se reúnem na constituição de Gaia.

É necessário frisar, novamente, que apenas ma medida em que Gaia age como um ser vivente que podemos aproximá-la da conepção de Simondon acerca do que é a vida. Pois, como esperamos ter demonstrado, o vivente para o filósofo nada mais é do que o seu agir: não um “algo" ou um "quê" mas um como. O modo de individuação é o índice constitutivo do ser em sua individualidade atual, o seu ser é a sua relacionalidade constituinte. Assim, Gaia, nessa concepção específica de indivíduo, por ser dita um ser vivente.

Deste modo, esperamos ter demonstrado como a individuação em Simondon oferece uma ferramente útil para compreendermos Gaia enquanto indivíduo vivente. Dentro do seu quadro teórico, o que vemos como o advento do Antropoceno e do novo regime climático é justamente uma instabilidade crescente que pode vir a comprometer a metaestabilidade de Gaia. Se chegarmos a tanto, como esperam diversas previsões, a partir destes potenciais assim liberados, poderemos ter uma nova individuação metaestável - uma nova Gaia - ou a vitória da entropia, do equilíbrio, se os viventes não mais restarem. Assim, torna-se imperativo o resguardo do equilíbrio metaestável que faz de Gaia um ser vivo.

\section{BIBLIOGRAFIA}

BARDIN, Andre. Epistemology and Political Philosophy in Gilbert Simondon. Londres: Springer, 2015 .

LATOUR, Bruno. Ressembling the social: an introduction to the actor network theory. Oxford : Oxford University Press, 2005

. Gabriel Tarde and the end of the social. Disponível em : www.brunolatour.com. Acesso a: 12/01/201

Face à Gaia:Huit conférences sur le Nouveau Régime Climatique. Paris:

La decouverte. 2015 .

LOVELOCK, James. Gaia: alerta final. Trad. de Jesus de Paula Assis e Vera de Paula Assis. Rio de Janeiro: Editora Intrínseca, 2010. 
. A Vingança de Gaia. Trad. de Ivo Korytowski. Rio de Janeiro: Editora Intrínseca, 2006 . Gaia: a new look in life on Earth. Oxford: Oxford University Press: 2000. LOVELOCK, James, MARGULIS, Lynn. Atomospheric homeostasis by and for life: the gaia hypothesis. In: Tellus, V. XXVII, 1974

SIMONDON, Gilbert. La individuación a la luz de las nociones de forma y información. Trad. de Pablo Esteban Rodriguéz. Cactus. Buenos Aires, 2009.

SCRAPE, Nikolas. Gaia's Game. In: Aferlive of Systems. Disponível em: https://monoskop.org/ Último acesso a 01/02/2016.

WIENER, Nobert. The human use of human beings: cybernetic and society. Tradução nossa. Londres. Free Association Books; 1990. 